\title{
Avaliação da sustentabilidade ambiental do uso de esgoto doméstico tratado na piscicultura
}

\section{Environmental sustainability evaluation of the treated sewage use in aquaculture}

\author{
Emanuel Soares dos Santos \\ Engenheiro de Pesca. Mestre em Engenharia de Pesca. Doutorando em Engenharia Civil, área de concentração em Saneamento Ambiental pela Universidade \\ Federal do Ceará (UFC). Bolsista do CNPq
}

\section{Suetônio Mota}

Engenheiro Civil e Sanitarista. Doutor em Saúde Ambiental. Professor Titular do Departamento de Engenharia Hidráulica e Ambiental do Centro de Tecnologia da UFC. Membro da Academia Cearense de Ciências

\begin{abstract}
André Bezerra dos Santos
Doutor em Ciências do Meio Ambiente. Professor Adjunto do Departamento de Engenharia Hidráulica e Ambiental do Centro de Tecnologia da UFC
\end{abstract}

\section{Cleto Augusto Baratta Monteiro}

Mestre em Desenvolvimento e Meio Ambiente. Doutor em Engenharia Civil, área de concentração em Saneamento Ambiental pela UFC.

Professor Adjunto da Universidade Federal do Piauí (UFPI)

\section{Rafahel Marques Macedo Fontenele}

Engenheiro de Pesca. Mestrando em Engenharia Civil, área de concentração em Saneamento Ambiental pela UFC. Bolsista Capes

\section{Resumo}

Este trabalho teve como objetivo avaliar a sustentabilidade ambiental do uso de esgoto doméstico tratado na piscicultura por meio do Índice de Sustentabilidade Ambiental para Reúso em Piscicultura (ISA $\mathrm{RP}_{\mathrm{P}}$ ), do Índice de Qualidade de Água para Reúso em Piscicultura (IQA $\mathrm{RP}_{\mathrm{P}}$ ) e do custo ambiental (entropia). Observouse, por meio do custo ambiental, que a piscicultura convencional causou a deterioração da qualidade da água que foi utilizada. Constatou-se que o sistema de piscicultura utilizando esgoto tratado, sem usar aeração, não causou efeito deletério significante à qualidade da água de reúso (efluente da estação de tratamento de esgoto - ETE). O sistema de piscicultura usando esgoto tratado, com aeração, resultou na melhoria de sua qualidade, quando comparado com o efluente da estação de tratamento, significando que essa prática resultou em um polimento no líquido utilizado. Ambos os sistemas de reúso de águas mostraram-se ambientalmente sustentáveis, o que indica a potencialidade do uso de esgoto doméstico tratado como fonte de água e alimento natural para a piscicultura.

Palavras-chave: gestão dos recursos hídricos; indicadores de sustentabilidade; reúso de água; sustentabilidade ambiental.

\begin{abstract}
This work aimed to evaluate the environmental sustainability of the treated sewage reuse on aquaculture by using the Environmental Sustainability Index of Aquaculture Reuse $\left(E S I_{A R}\right)$, Water Quality Index of Aquaculture Reuse $\left(W I_{A R}\right)$ and environmental cost (entropy). For conventional aquaculture, a water quality deterioration of the fish tanks was observed by the environmental cost. When treated sewage was used in tanks without external aeration, it was not verified a remarkable water quality deterioration. However, for the tanks externally aerated and fed with treated sewage there was a water quality improvement, in other words a polishing step was taking place. All the systems analyzed showed to be environmentally sustainable, which indicates that the treated sewage can be considered a good water source for aquaculture.
\end{abstract}

Keywords: water bodies management; sustainability index; water reuse; environmental sustainability. 


\section{Introdução}

Nos dias atuais, sabe-se que a problemática da escassez de água no planeta não está relacionada com a quantidade de água existente, mas, sim, com a desigualdade na distribuição nas diversas regiões e com a sua qualidade. Essa questão se torna ainda mais grave quando é admitida a crescente degradação dos recursos hídricos.

Com o crescente aumento da população humana, eleva-se cada vez mais a pressão sobre os recursos hídricos. Isso ocorre tanto do ponto de vista da captação de volumes, cada vez maior para o consumo humano direto, como para abastecer as diversas atividades que dão sustentação ao padrão de consumo da sociedade, como nas atividades industriais e nas atividades agrícolas, sendo esta última responsável pelo consumo de aproximadamente 70\% de toda a água disponível no planeta (TELLES, 2006; TUNDISI, 2008).

A aquicultura é mais uma atividade a competir com inúmeras outras pelo recurso água. O desenvolvimento desse tipo de atividade produtiva, entretanto, apresenta riscos de deteriorar a qualidade e comprometer a quantidade da água, podendo contribuir para o declínio da qualidade ambiental, social e econômica (TIAGO; GIANESELLA, 2003). Atualmente, a aquicultura enfrenta o desafio de moldar-se ao conceito de sustentabilidade, o que implica agregar novos valores à produção de conhecimento e às práticas do setor (ELER; MILLANI, 2007).

$\mathrm{Na}$ busca do desenvolvimento de atividades que estejam de acordo com os objetivos da sustentabilidade, nas quais as atividades devem ser economicamente viáveis, ecologicamente corretas e socialmente justas, é necessário considerar a prática do reúso de águas como uma das boas opções para a problemática da oferta hídrica (SANTOS et al, 2009a), além de ser considerado como uma medida de controle da poluição, pois, com a adoção de tal prática evita-se o lançamento de esgotos nos corpos de água (MOTA, 2008). Dessa forma o uso de efluentes domésticos pode ser considerado uma ferramenta para a gestão dos recursos hídricos.

Segundo Christofidis (2001), a Política Nacional de Recursos Hídricos como ferramenta de gestão deve revitalizar sua oferta e otimizar sua utilização, de modo que os benefícios possam ser equitativos, atingir o maior número de pessoas, evitando o desperdício e a poluição, garantindo, assim, a proteção e o uso múltiplo da água.

Um dos desafios da construção do desenvolvimento sustentável é criar instrumentos de mensuração capazes de prover informações que facilitem a avaliação do grau de sustentabilidade das sociedades, monitorem as tendências de seu desenvolvimento e auxiliem na definição de metas de melhoria (POLAZ; TEIXEIRA, 2009).

É urgente no campo do saneamento ambiental a estruturação de um sistema de indicadores para avaliar as condições ambientais pela necessidade da existência de instrumentos confiáveis para respaldar o planejamento, a execução e avaliação de ação pública (BORJA; MORAES, 2003).
Os indicadores constituem componentes de avaliação ambiental importantes, capazes de quantificar alterações na qualidade do meio ambiente e na quantidade de recursos naturais, bem como avaliar os esforços desenvolvidos visando à melhoria do meio ambiente ou à mitigação de sua degradação (MATTAR NETO; KRÜGER; DZIEDZIC, 2009). O principal papel dos indicadores é transformar dados em informações relevantes para os tomadores de decisão e o público (CALIJURI et al, 2009).

Tendo um conjunto de indicadores como ferramentas para o planejamento, existirão parâmetros para melhor aproveitamento dos recursos naturais e também para a indicação de medidas preventivas de degradação ambiental e consequentes prejuízos econômicos (MATTAR NETO; KRÜGER; DZIEDZIC, 2009)

Por meio dos valores dos parâmetros de qualidade de água, é possível definir indicadores que poderão refletir o grau de sustentabilidade de determinada atividade, e o acompanhamento destes, desde a captação da água para o consumo até o tratamento dos efluentes, constitui instrumento de gestão ambiental da água.

O Índice de Qualidade de Água (IQA), um dos primeiros do mundo para avaliação da qualidade de água, foi criado pela Agência Nacional Americana de Saneamento (NSF, do inglês National Sanitation Foundation) com base na análise de nove parâmetros físico-químicos e biológicos. Dessa forma, criou-se uma ferramenta de gestão padronizada e aceita em todo o mundo para o monitoramento da qualidade da água de rios (SIMÕES et al., 2008).

O maior problema com a elaboração do IQA é classificar a qualidade da água em excelente, bom, regular, ruim e pobre, considerando que a qualidade da água é um conceito que depende da sua aplicação, como para a irrigação, recreação, uso industrial, abastecimento público de água, a manutenção da vida aquática, entre outras (SIMÕES et al, 2008). Dessa forma, torna-se necessário o desenvolvimento de indicadores específicos para retratar melhor as condições de cada atividade.

Este trabalho teve como objetivo avaliar a sustentabilidade ambiental da prática do uso de esgoto doméstico tratado na piscicultura por meio de três índices propostos: Índice de Sustentabilidade Ambiental para Reúso em Piscicultura (ISA ${ }_{\mathrm{RP}}$ ); Índice de Qualidade de Água para Reúso em Piscicultura (IQA $A_{\mathrm{RP}}$ ); custo ambiental (entropia).

\section{Metodologia}

\section{Descrição da área e procedimentos experimentais do reúso de água em piscicultura}

Os experimentos foram realizados no Centro de Pesquisa sobre Tratamento de Esgotos e Reúso de Águas, situado junto a uma estação de tratamento de esgoto (ETE) da Companhia de Água e Esgoto do Ceará (Cagece), no município de Aquiraz, Ceará, Brasil.

O sistema de tratamento é composto por quatro lagoas de estabilização em série, constando de uma anaeróbia, uma facultativa e 
duas de maturação, sendo a água de abastecimento dos viveiros do sistema de reúso retirada da última unidade. Foram utilizados, no experimento, três viveiros com $50 \mathrm{~m}^{3}$ de volume, nos quais foram estocados alevinos de tilápia do Nilo, Oreochromis niloticus, na densidade experimental de 12 alevinos $/ \mathrm{m}^{2}$ (600 alevinos/viveiro) e oferta da ração balanceada. A descrição dos tratamentos experimentais da piscicultura segue na Tabela 1.

A água bruta utilizada para abastecimento do tanque do tratamento 3, foi captada em uma pequena barragem em um curso de água que passa por dentro do terreno da mencionada ETE.

Ao final do experimento, foram determinados os dados referentes aos parâmetros zootécnicos de peso médio dos peixes e sobrevivência, para que fosse calculado o ganho de biomassa no período experimental.

\section{Coletas e análises da qualidade de água}

Foram coletadas amostras da água bruta, do esgoto bruto, do efluente da ETE e dos viveiros experimentais com o objetivo de fazer a caracterização da água de entrada e saída dos sistemas em estudo nos seguintes pontos:

1. afluente à ETE $\rightarrow$ esgoto bruto, coletado após a calha Parshall;

2. efluente da ETE $\rightarrow$ esgoto tratado, coletado na saída da última lagoa de maturação;

3. efluentes dos viveiros experimentais $\rightarrow$ dos dois tanques de cultivo em esgoto tratado e do tanque de cultivo em água bruta; amostras coletadas nas saídas dos tanques.

Foram realizadas in loco as análises de oxigênio dissolvido (OD). Para as determinações de demanda bioquímica de oxigênio (DBO), $\mathrm{pH}$, amônia, fósforo total e coliformes termotolerantes, as amostras foram devidamente acondicionadas e encaminhadas ao Laboratório de Saneamento (Labosan) do Departamento de Engenharia Hidráulica e Ambiental (DEHA) da Universidade Federal do Ceará (UFC).

As análises de laboratório foram feitas seguindo metodologia apresentada no Standard Methods (APHA, 2005).

\section{Padrões de qualidade de água assumidos na avaliação de sustentabilidade ambiental}

$\mathrm{Na}$ Tabela 2, constam os parâmetros de qualidade de água, com seus respectivos valores de referência conforme propostos pelo Programa de Pesquisa em Saneamento Ambiental (Prosab) (FLORÊNCIO et al, 2006), além de valores citados por Boyd e Tucker (1990) para aquicultura e Colt (2006) para sistemas de reúso em aquicultura, os quais foram utilizados como base para definição dos limites propostos para as análises de sustentabilidade ambiental.

A partir dessas informações foram definidos os valores máximos e mínimos a serem assumidos para estabelecimento do fator de normalização, conforme será mostrado posteriormente.
Tabela 1 - Descrição dos tratamentos experimentais para análise de sustentabilidade do reúso de água em piscicultura

\begin{tabular}{lll} 
Tratamento & Fonte de Água & Descrição \\
T-1 & Esgoto tratado & Sem aeração \\
T-2 & Esgoto tratado & $\begin{array}{l}\text { Aerador mecânico com } 3 / 4 \text { de HP } \\
\text { funcionando das 21-06h }\end{array}$ \\
T-3 & Água bruta & Sem aeração; teste em branco \\
\hline
\end{tabular}

\section{Metodologia para avaliação da sustentabilidade ambiental}

Com base nos indicadores de qualidade de água foi proposto o Índice de Qualidade de Água para Reúso em Piscicultura $\left(\mathrm{IQA}_{\mathrm{RP}}\right)$ e o Índice de Sustentabilidade Ambiental para Reúso em Piscicultura $\left(\mathrm{ISA}_{\mathrm{RP}}\right.$ ), sendo que, para este último índice, também foi considerada a produtividade piscícola. Para completar a avaliação, foi feito o cálculo do custo ambiental (entropia) dos sistemas analisados.

Os parâmetros físico-químicos e microbiológicos foram utilizados na caracterização da água e do efluente sanitário individualmente em cada ponto de coleta. Porém, as análises foram feitas de forma a constatar as mudanças ocorridas como resultado do uso dado à água e ao efluente sanitário. Caracterizaram-se os usos da água em quatro diferentes sistemas, conforme mostrado na Tabela 3.

\section{Normalização dos indicadores de qualidade de água e produtividade}

Os parâmetros de qualidade de água e a produtividade foram normalizados por meio da transformação do valor real obtido do indicador em um quantum que varia entre zero e um, de forma que o valor um significa a melhor condição de sustentabilidade alcançada e o valor zero o desempenho mais desfavorável, ou seja, sustentabilidade não alcançada (RABELO, 2007).

Para realizar a normalização, torna-se necessária a definição dos limites máximos e mínimos da escala que será adotada. Na Tabela 4 , estão expostos os valores máximos e mínimos adotados assim como as respectivas justificativas.

A produtividade foi o indicador de rendimento zootécnico utilizado no $\mathrm{ISA}_{\mathrm{RP}}$ Para avaliação desse indicador, tomaram-se como base as características do sistema de cultivo aplicado no experimento denominado semi-intensivo, o qual, segundo Zimmermann e Fitzsimmons (2004) é capaz de gerar uma produção de 2.500 a $12.500 \mathrm{~kg} /$ (ha.safra), com valores de biomassa econômica em torno de 5.000 a 7.000 kg/(ha.safra) (KUBITZA, 2000). Baseado nesses valores foi adotado como valor máximo da escala de normalização 7,5 ton/(ha.safra) e o valor mínimo 2,5 ton/(ha.safra).

O próximo passo foi definir o número de classes que seriam adotadas para, então, calcular o intervalo das classes. Foram definidas 11 classes distribuídas igualmente no intervalo de 0 a 1 . Para a definição 
do intervalo de classe de normalização (I ) aplicada aos indicadores OD, DBO, fósforo total, amônia e a produtividade, utilizou-se a Equação 1:

$I_{c}=\frac{\left|V_{f}-V_{i}\right|}{N_{c}-1}$

Equação 1

Onde:

$I_{c}$ : intervalo de classe de normalização;

$\mathrm{V}_{\mathrm{f}}$ : valor considerado indesejado ou insustentável para o indicador que está sendo avaliado;

$\mathrm{V}_{\mathrm{i}}$ : valor considerado desejado ou sustentável para o indicador que está sendo avaliado; e

$\mathrm{N}_{c}$ : numero de classes estabelecidas;

$\mathrm{O}$ pH tem como peculiaridade o valor desejado que está no meio da faixa considerada desejável ( 6 a 9); dessa forma, a equação foi aplicada em duas faixas, considerando o valor 7,5 como o mais desejável. Assim, em cada uma das faixas a escala diminuiu ou aumentou até o valor indesejado (6 e 9).

Já para a normalização dos valores de coliformes termotolerantes, foi assumida a curva logarítmica para o decaimento das concentrações microbianas.
Na Tabela 5, é possível observar os valores estabelecidos por meio da equação de intervalo de classe de normalização para os indicadores assumidos como referência, assim como o respectivo fator de normalização que foi aplicado a eles para o cálculo dos ISA $A_{R P}$ e IQA $A_{R P}$. Para a apresentação dos resultados da normalização, adaptou-se a metodologia aplicada e sugerida por Pesce e Wunderlin (2000).

A partir dos valores apresentados na Tabela 5 é possível definir as equações de normalização referentes aos indicadores apresentados, conforme exposto na Tabela 6 . O valor de cada indicador substitui o " $\mathrm{x}$ " em sua respectiva equação (Tabela 6), fornecendo o valor normalizado " $\mathrm{y}$ ".

\section{Índice de Sustentabilidade Ambiental para Reúso em Piscicultura}

$\mathrm{O} \mathrm{ISA}_{\mathrm{RP}}$ foi calculado com base na produtividade da piscicultura e nos parâmetros de qualidade de água. Por sua vez, o índice foi calculado a partir de valores (zero a um), conforme a metodologia de normalização anteriormente citada, e estabelecendo pesos variando de zero a três, conforme a importância de cada indicador, então, calculando-se a média geométrica.

Tabela 2 - Padrões de qualidade de água adotados pela legislação federal ambiental vigente e recomendadas pela bibliografia especializada para aquicultura e sistema de reúso em aquicultura

$\begin{array}{lll}\text { Parâmetro } & \text { Referência } & \text { Descrição } \\ \text { OD } & \text { Colt (2006) } & \text { Sistemas de reúso em aquicultura } \\ \text { pH } & \text { Colt (2006) } & \text { Sistemas de reúso em aquicultura } \\ \text { DBO } & \text { Boyd; Tucker (1990) } & \text { Sistemas de aquicultura } \\ \text { Amônia total } & \text { Colt }(2006) & \text { Sistemas de reúso em aquicultura } \\ \text { Fósforo total } & \text { Boyd; Tucker }(1990) & \text { Sistemas de aquicultura } \\ \text { Coliformes termotolerantes } & \text { Prosab } & \text { No tanque }- \text { afluente ao tanque de reúso em aquicultura }\end{array}$

OD: oxigênio dissolvido; DBO: demanda bioquímica de oxigênio; NMP: número mais provável.

Tabela 3 - Sistemas avaliados quanto à sustentabilidade ambiental e seus respectivos afluentes e efluentes

$\begin{array}{lll}\text { Sistemas avaliados } & \text { Afluente } & \text { Efluente } \\ \text { Piscicultura convencional } & \text { Água bruta } & \text { Efluente de piscicultura } \\ \text { Lagoas de estabilização } & \text { Esgoto bruto } & \text { Esgoto tratado } \\ \text { Reúso sem aeração } & \text { Esgoto tratado (água de reúso) } & \text { Efluente de piscicultura com reúso, sem aeração } \\ \text { Reúso com aeração } & \text { Esgoto tratado (água de reúso) } & \text { Efluente de piscicultura com reúso, com aeração }\end{array}$

Tabela 4 - Limites mínimo e máximo dos indicadores de qualidade de água e a respectiva justificativa para os seus usos na composição do Índice de Qualidade de Água para Reúso em Piscicultura $\left(\mathrm{IQA}_{\mathrm{RP}}\right)$ e o Índice de Sustentabilidade Ambiental para Reúso em Piscicultura (ISA $\mathrm{RP}$ )

\begin{tabular}{|c|c|c|c|}
\hline Parâmetro & Mínimo & Máximo & Justificativa \\
\hline OD (mg. $\left.L^{-1}\right)$ & $\leq 1,0$ & $\geq 7,0$ & Valor para sistema de reúso como meio da escala; \\
\hline $\mathrm{pH}$ & 6 & 9 & Faixa recomendada para sistemas de reúso; \\
\hline DBO (mg. $\left.L^{-1}\right)$ & $\leq 5$ & $\geq 400$ & Limite máximo da faixa equivalente ao valor médio para esgoto sanitário; \\
\hline Amônia total (mg. $\left.\mathrm{L}^{-1}\right)$ & $\leq 5$ & $\geq 20$ & $\begin{array}{l}\text { Limite mínimo da faixa equivalente ao valor proposto para cultivo de } \\
\text { peixes em sistema de reúso; }\end{array}$ \\
\hline Fósforo total $\left(\mathrm{mg} \cdot \mathrm{L}^{-1}\right)$ & $\leq 0,05$ & $\geq 6,0$ & Limite máximo da faixa equivalente ao valor médio para esgoto sanitário; \\
\hline Coliformes termotolerantes (NMP/100 mL) & $\leq 10^{3}$ & $\geq 10^{6}$ & $\begin{array}{l}\text { Valor médio da escala do fator de normalização }\left(5 \times 10^{3} \mathrm{NMP} / 100 \mathrm{~mL}\right) \\
\text { coincidindo com o ponto médio do intervalo proposto pelo Prosab. }\end{array}$ \\
\hline
\end{tabular}

OD: oxigênio dissolvido; DBO: demanda bioquímica de oxigênio. 
Conforme adaptação da metodologia aplicada por Nascimento e

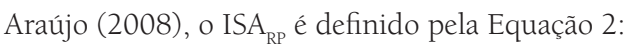

$\mathrm{ISA}_{\mathrm{RP}}=\sum_{=1}^{\mathrm{m}}\left[\frac{\mathrm{E}_{\mathrm{i}} \mathrm{P}_{\mathrm{i}}}{\mathrm{mP} \mathrm{m}_{\operatorname{maxi}}}\right]$

Equação 2 Custo ambiental (entropia - $\omega$ )

Onde:

$\mathrm{ISA}_{\mathrm{RP}}$ : Índice de Sustentabilidade Ambiental para Reúso em Piscicultura;

$\mathrm{E}_{\mathrm{i}}$ : escore do i-ésimo indicador;

$\mathrm{P}_{\mathrm{i}}$ : peso do i-ésimo indicador;

$\mathrm{P}_{\text {maxi }}$ : peso máximo do i-ésimo indicador;

i: $1, \ldots, m$; $\mathrm{e}$

m: número de indicadores.

\section{Índice de Qualidade de Água para reúso em piscicultura $\left(\mathrm{IQA}_{\mathrm{RP}}\right)$}

Foi utilizada uma adaptação do índice mínimo de qualidade de água $\left(\mathrm{IQA}_{\min }\right)$ proposto por Pesce e Wunderlin (2000), o qual, originalmente, era calculado a partir da média das concentrações normalizadas de OD, Turbidez e Fósforo Total. A forma adaptada, chamada de IQA $A_{\mathrm{RP}}$ usada nesta avaliação, consta da Equação 3:

$$
\mathrm{IQA}_{\mathrm{RP}}=\left(\frac{\mathrm{NOD}+\mathrm{NpH}+\mathrm{NDBO}+\mathrm{NAmônia}+\mathrm{NFT}+\mathrm{NCT}}{6}\right) \times 100
$$

Equação 3

Onde:

$\mathrm{IQA}_{\mathrm{RP}}$ : Índice de Qualidade de Água para reúso em piscicultura; NOD: valor normalizado da concentração de oxigênio dissolvido; $\mathrm{NpH}$ : valor normalizado de $\mathrm{pH}$;

NDBO: valor normalizado da concentração de demanda bioquímica de oxigênio;

NAmônia: valor normalizado da concentração de amônia;

NFT: valor normalizado da concentração de fósforo total; e

NCT: valor normalizado da concentração de coliformes termotolerantes.

$\mathrm{Na}$ Tabela 7, apresenta-se a classificação adotada para avaliação dos resultados de $\mathrm{ISA}_{\mathrm{RP}}$ e IQA $\mathrm{IP}_{\mathrm{RP}}$, os quais tiveram seus valores de referência conforme os aplicados por Nascimento e Araújo (2008). Quanto maior o resultado obtido, maior será o nível de benefícios ambientais e de qualidade de água.

Para a complementação da análise de sustentabilidade ambiental, foi realizado o cálculo da entropia, conforme a metodologia aplicada por Pereira (2004), que indica o quanto um determinado processo consegue transformar a energia disponível (E) em trabalho ( $\omega)$, tendo o mínimo de desperdício ( $\varepsilon$ ), o qual, nesse caso, trata-se de poluição, também chamado de custo ambiental. Essa relação está representada na Equação 4 e Equação 5.

$E=\omega+\varepsilon$

Equação 4

$\omega=\mathrm{E}-\varepsilon$

Equação 5

Os cálculos do custo ambiental, na forma de entropia, foram realizados em termos de $\mathrm{DBO}$, amônia, fósforo total e coliformes termotolerantes.

\section{Resultados}

\section{Resultados dos indicadores de qualidade de água e produtividade}

Os resultados médios dos indicadores de qualidade de água, assim como dos desvios-padrão, estão apresentados na Tabela 8. Os dados foram comparados por meio da ANOVA e Teste de Tukey ( $\mathrm{p} \leq$ $0,05)$, e os resultados estão indicados pelas letras subsequentes aos valores, ressaltando-se que letras diferentes indicam diferença estatisticamente significativa.

Os resultados referentes à produtividade piscícola dos sistemas avaliados foram de $4.717,5 \mathrm{~kg} /$ (ha.safra) para o sistema de piscicultura convencional; $1.562,0 \mathrm{~kg} /$ (ha.safra) para o sistema de reúso na piscicultura sem aeração; 7.018,5 kg/(ha.safra) para o sistema de

Tabela 5 - Fator de normalização dos parâmetros de qualidade de água e da produtividade, indicadores utilizados para cálculo do ISA ${ }_{\mathrm{RP}}$ e IQA $\mathrm{RP}_{\mathrm{R}}$

\begin{tabular}{|c|c|c|c|c|c|c|c|c|c|c|c|}
\hline \multirow{2}{*}{ Parâmetros } & \multicolumn{11}{|c|}{ Fator de normalização } \\
\hline & 1 & 0,9 & 0,8 & 0,7 & 0,6 & 0,5 & 0,4 & 0,3 & 0,2 & 0,1 & 0 \\
\hline $\mathrm{OD}\left(\mathrm{mg} \cdot \mathrm{L}^{-1}\right)$ & $\geq 7,0$ & 6,0 & 5,0 & 4,5 & 4,0 & 3,5 & 3,0 & 2,5 & 2,0 & 1,5 & $\leq 1,0$ \\
\hline \multirow{2}{*}{$\mathrm{pH}$} & 7,5 & 7,65 & 7,8 & 7,95 & 8,10 & 8,25 & 8,40 & 8,55 & 8,70 & 8,85 & $\geq 9,0$ \\
\hline & 7,5 & 7,35 & 7,20 & 7,05 & 6,90 & 6,75 & 6,60 & 6,45 & 6,30 & 6,15 & $\leq 6,0$ \\
\hline DBO (mg. $\left.\mathrm{L}^{-1}\right)$ & $\leq 5,0$ & 44,5 & 84 & 123,5 & 163 & 202,5 & 242 & 281,5 & 321 & 360,5 & $\geq 400$ \\
\hline Amônia (mg. $\mathrm{L}^{-1}$ ) & $\leq 2,0$ & 3,8 & 5,6 & 7,4 & 9,2 & 11,0 & 12,8 & 14,6 & 16,4 & 18,2 & $\geq 20$ \\
\hline $\mathrm{FT}\left(\mathrm{mg} \cdot \mathrm{L}^{-1}\right)$ & $\leq 0,05$ & 0,645 & 1,24 & 1,835 & 2,43 & 3,025 & 3,62 & 4,215 & 4,81 & 5,405 & $\geq 6,0$ \\
\hline CT (NMP/100mL) & $\leq 10$ & 50 & 100 & 500 & $10^{3}$ & $5 \times 10^{3}$ & $10^{4}$ & $5 \times 10^{4}$ & $10^{5}$ & $5 \times 10^{5}$ & $\geq 10^{6}$ \\
\hline Prod. (ton/(ha.safra)) & $\geq 7,5$ & 7 & 6,5 & 6 & 5,5 & 5 & 4,5 & 4 & 3,5 & 3 & $\geq 2,5$ \\
\hline
\end{tabular}

OD: oxigênio dissolvido; DBO: demanda bioquímica de oxigênio; FT: fósforo total; CT: coliformes termotolerantes; Prod.: produtividade. 
reúso na piscicultura com aeração. O sistema de lagoa de estabilização apresentou produtividade nula, por não se tratar de um sistema de produção de peixes.

\section{Resultados do ISA $A_{R P}$ e IQA}

Muga e Mihelcic (2008) utilizaram os gráficos de radar como ferramenta de auxílio à análise de sustentabilidade de diferentes tecnologias de tratamento de esgotos, pois estes facilitam a visualização dos resultados, assim como suas interações.

Na Figura 1, é possível observar em gráficos de radar, os resultados dos indicadores de qualidade de água e de produtividade normalizados para os quatro sistemas avaliados. Quanto mais longe do centro do gráfico, melhores são os resultados, pois na escala do gráfico o centro representa o zero (0 - condição de sustentabilidade não alcançada) e na extremidade externa está o um (1 - condição de sustentabilidade alcançada). Dessa forma, avalia-se a sustentabilidade ambiental a partir da comparação do tamanho

Tabela 6 - Equações de normalização dos indicadores de qualidade de água e da produtividade utilizados para cálculo do ISA ${ }_{\mathrm{RP}}$ e IQA $\mathrm{RP}_{\mathrm{RP}}$

\begin{tabular}{lc}
\hline Indicador $(x)$ & Equação de normalização \\
\hline OD $\left(m g . L^{-1}\right)$ & $y=0,1667 x-0,1667$ \\
pH $(7,5-9,0)$ & $y=-0,6667 x+6$ \\
pH $(7,5-6,0)$ & $y=0,6667 x-4$ \\
\hline DBO $\left(m g . L^{-1}\right)$ & $y=-0,0025 x+1,0127$ \\
\hline Amônia $\left(m g . L^{-1}\right)$ & $y=-0,0556 x+1,1111$ \\
\hline Fósforo total (mg. $\left.L^{-1}\right)$ & $y=-0,1681 x+1,0084$ \\
\hline Coliformes termotolerantes (NMP/100mL) & $y=-0,087 \ln (x)+1,2153$ \\
\hline Produtividade (ton/(ha.safra)) & $y=0,2 x-0,5$
\end{tabular}

OD: oxigênio dissolvido; DBO: demanda bioquímica de oxigênio.

Tabela 7 - Classificação adotada para avaliação dos resultados de ISA e IQA $A_{R P}$

\begin{tabular}{lcc} 
& \multicolumn{2}{c}{ Resultados } \\
\cline { 2 - 3 } Classificação & $\mathrm{ISA}_{\mathrm{RP}}$ & $\mathrm{IQA}_{\mathrm{RP}}$ \\
Baixo & $0,0-0,4$ & $0-40$ \\
Médio & $0,41-0,7$ & $41-70$ \\
Alto & $0,71-1,0$ & $71-100$ \\
\hline
\end{tabular}

das áreas correspondentes às situações antes e depois da atividade: quanto maior a área, maior é a sustentabilidade da atividade.

Na Figura 1A, referente ao sistema de lagoas de estabilização, evidencia-se a melhoria dos indicadores da qualidade do esgoto tratado em relação ao esgoto bruto, com exceção do indicador pH. Porém, esse fato não chegou a inviabilizar o processo, comprovando a sustentabilidade do tratamento de esgoto em sistema de lagoas de estabilização, segundo esse critério.

Quanto ao sistema de piscicultura convencional (Figura 1B), observa-se que, excetuando-se o indicador de coliformes termotolerantes, o qual apresentou diminuição nas suas concentrações, e o indicador de produtividade, pois a água, sem receber qualquer uso, não é capaz de produzir alimento, todos os outros mostraram que o uso da água bruta na piscicultura lhe causa efeitos deletérios.

Esse resultado era esperado, pois a água bruta agora passa a ser efluente de um processo produtivo; no entanto, deseja-se mostrar que é possível utilizar esgoto doméstico tratado na piscicultura, e com isso evitar-se que essa atividade degrade desnecessariamente a qualidade da água bruta que poderá ser aproveitada em outros usos. Dessa forma, o reúso de água exerce importante papel como ferramenta de gestão dos recursos hídricos.

Quanto à atividade de reúso sem aeração (Figura 1C), observa-se pequena variação na qualidade do efluente, constatando-se melhoria significativa apenas em termos dos compostos nitrogenados, como indica o aumento do valor do ISA $_{\mathrm{RP}}$ da amônia. Os valores de $\mathrm{ISA}_{\mathrm{RP}}$ da DQO e do $\mathrm{pH}$ foram ligeiramente mais baixos para o efluente do tanque, representando uma pequena redução na qualidade da água.

Ao avaliar a atividade da piscicultura com o uso do esgoto tratado na presença de aeração (Figura 1D), pode-se constatar, por meio do aumento do valor do ISA $_{\mathrm{RP}}$, que houve melhoria nos indicadores OD, amônia e produtividade. É válido salientar o valor bastante elevado de produtividade desse sistema, estando superior até mesmo ao da piscicultura tradicional.

Comparando os níveis de sustentabilidade e de qualidade de água encontrados, por meio dos resultados de $\mathrm{ISA}_{\mathrm{RP}}$ e IQA $\mathrm{RP}_{\mathrm{RP}}$ é possível avaliar as mudanças ocorridas na qualidade da água/efluente a partir dos seus usos (Tabela 9).

Tabela 8 - Resultados médios dos parâmetros de qualidade de água analisados

$\begin{array}{lcccccc}\text { Parâmetros } & \text { Água } & \text { ET } & \text { EB } & \text { T1 } & \text { T2 } & \text { T3 } \\ \text { OD (mg/L) } & 4,95 \pm 1,84 a & 3,26 \pm 1,04 a b & 1,07 \pm 1,34 b & 3,40 \pm 0,26 a b & 5,34 \pm 0,97 a & 3,75 \pm 2,51 a \\ \text { pH } & 7,34 \pm 0,39 a & 7,81 \pm 0,02 a & 7,18 \pm 0,00 a & 8,03 \pm 0,51 a & 8,17 \pm 0,12 a & 7,98 \pm 0,47 a \\ \text { DBO (mg/L) } & 14,20 \pm 6,3 \mathrm{c} & 63,49 \pm 33,1 \mathrm{ab} & 228,16 \pm 68,2 \mathrm{~d} & 86,19 \pm 32,3 \mathrm{a} & 66,35 \pm 38,6 \mathrm{a} & 37,97 \pm 36,2 \mathrm{bc} \\ \text { Amônia (mg/L) } & 0,2 \pm 0,16 \mathrm{~b} & 6,5 \pm 4,48 \mathrm{a} & 31,8 \pm 13,87 \mathrm{c} & 2,7 \pm 1,32 \mathrm{a} & 3,5 \pm 1,95 \mathrm{a} & 0,5 \pm 0,31 \mathrm{~b} \\ \text { FT (mg/L) } & 0,2 \pm 0,1 \mathrm{~b} & 3,4 \pm 1,4 \mathrm{a} & 3,4 \pm 1,0 & 3,9 \pm 0,8 \mathrm{a} & 4,0 \pm 0,6 \mathrm{a} & 0,2 \pm 0,2 \mathrm{~b} \\ \text { CT (NMP/100ml) } & 313,5 \mathrm{ab} & 573,2 \mathrm{~b} & 1,71 \times 10^{7} \mathrm{c} & 217,5 \mathrm{ab} & 269,0 \mathrm{ab} & 85,6 \mathrm{a}\end{array}$

Água: água bruta; ET: esgoto tratado; EB: esgoto bruto; T1: tanque com esgoto tratado (sem aeração); T2: tanque com esgoto tratado (com aeração); T3: tanque com água; OD: oxigênio dissolvido; DBO: demanda bioquímica de oxigênio; FT: fósforo total; CT: coliformes termotolerantes. Obs.: Letras diferentes indicam diferença estatisticamente significante para ANOVA e Teste de Tukey $(p \leq 0,05)$. 


\section{Lagoas de Estabilização}

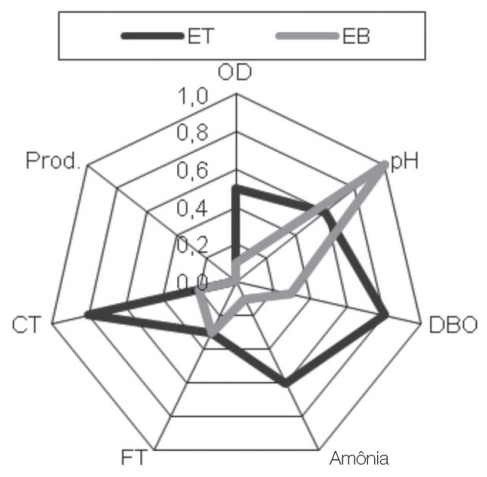

Reúso sem aeração

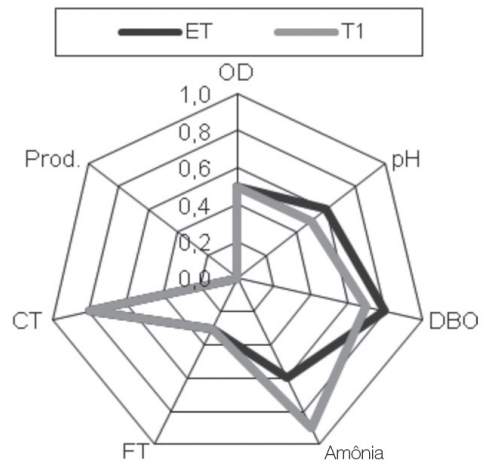

Piscicultura convencional

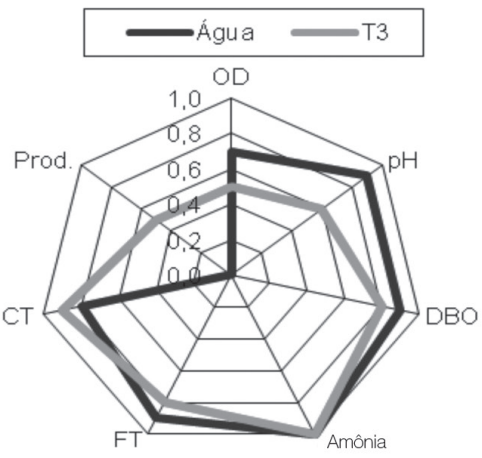

Reúso com aeração

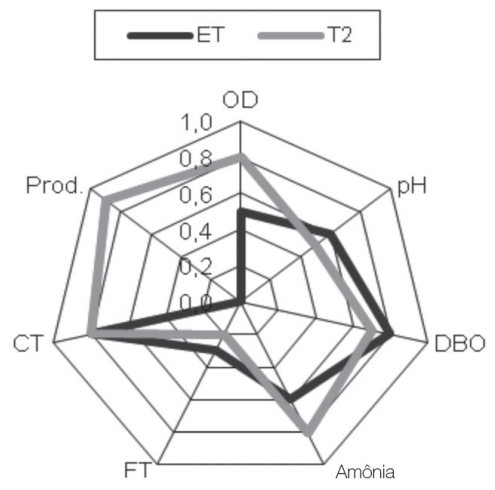

Figura 1 - Gráficos de radar relacionando os resultados de Índice de Sustentabilidade Ambiental para Reúso em Piscicultura (ISA ${ }_{\mathrm{RP}}$ ) dos pontos analisados, com os respectivos sistemas aos quais fazem parte. T1: tanque com esgoto tratado (sem aeração); T2: tanque com esgoto tratado (com aeração); T3: tanque com água bruta; DBO: demanda bioquímica de oxigênio; FT: fósforo total; CT: coliformes termotolerantes; ET: esgoto tratado; EB: esgoto bruto; OD: oxigênio dissolvido.

O ISA ${ }_{\mathrm{RP}}$ do sistema de lagoas de estabilização manteve-se classificado como baixo, porém seu valor absoluto apresentou aumento significativo, de 0,12 para 0,35. Já para o IQA $A_{R P}$ percebe-se que este apresentou melhoria ainda mais acentuada, elevando-se do nível baixo para o médio.

O ISA $A_{R P}$ e o IQA $A_{R P}$ do sistema de piscicultura tradicional mantiveram a classificação alta. É válido observar que para o IQA $A_{R P}$ houve uma queda de aproximadamente seis pontos percentuais na qualidade da água, de 88,5 para 82,3\%.

Para a piscicultura em esgoto tratado sem aeração mecânica não houve mudanças significativas nos valores obtidos de $I S A_{R P} e$ $\mathrm{IQA}_{\mathrm{RP}}$, estando assim os níveis de sustentabilidade e de qualidade de água inalterados, indicando a sustentabilidade do uso de esgoto tratado na piscicultura.

$\mathrm{Na}$ avaliação do sistema de piscicultura em esgoto tratado com aeração, percebe-se que houve mudança significativa para o ISA ${ }_{\mathrm{RP}}$, tendo o nível de sustentabilidade passado de baixo para médio, enquanto o IQA $\mathrm{RP}_{\mathrm{RP}}$ apresentou aumento de aproximadamente quatro pontos percentuais, elevando-se de 64,7 para $68,4 \%$. Esses resultados reforçam a sustentabilidade do uso de esgoto doméstico tratado na piscicultura, salientando o efeito benéfico da aeração mecânica nos resultados obtidos.

\section{Resultados do custo ambiental (Entropia - $\omega)$}

Na Tabela 10 é possível observar os valores referentes à entropia, em termos de DBO, amônia, fósforo total e coliformes termotolerantes, para os quatro sistemas analisados.

O sistema de lagoas de estabilização foi o que apresentou os melhores resultados de entropia, resultando na melhoria da qualidade do esgoto bruto, o que confirma a sustentabilidade do tratamento de esgoto usando essa tecnologia.

Dentre os sistemas avaliados, a piscicultura convencional foi a que apresentou os menores valores de entropia, o que indica o maior custo ambiental, isto é, o maior nível de poluição. Isso ocorre por estar se utilizando, inicialmente, uma água de boa qualidade, a qual tem sua composição original deteriorada, principalmente pelo aumento da matéria orgânica, indicada pela DBO $(-23,77)$. 
Tabela 9 - Resultados de ISA $\mathrm{RP}_{\mathrm{RP}}$ IQA $\mathrm{RP}_{\mathrm{R}}$ e suas determinadas avaliações conforme a escala de níveis pré-determinados

\begin{tabular}{|c|c|c|c|c|c|}
\hline \multirow[b]{2}{*}{ Sistemas } & \multirow[b]{2}{*}{ Afluente/Efluente } & \multicolumn{4}{|c|}{ Índices e avaliações } \\
\hline & & $I S A_{R P}$ & Sustentabilidade & $\underset{(\%)}{I Q A_{R P}}$ & Qualidade \\
\hline \multirow{2}{*}{ Lagoas de estabilização } & Esgoto bruto & 0,12 & Baixa & 28,0 & Baixa \\
\hline & Esgoto tratado & 0,35 & Baixo & 64,7 & Média \\
\hline \multirow{2}{*}{ Piscicultura convencional } & Água bruta & 0,46 & Média & 88,5 & Alta \\
\hline & $\mathrm{T}-3$ & 0,48 & Média & 82,3 & Alta \\
\hline \multirow{2}{*}{ Reúso sem aeração } & Esgoto tratado & 0,35 & Baixa & 64,7 & Média \\
\hline & $\mathrm{T}-1$ & 0,36 & Baixa & 65,1 & Média \\
\hline \multirow{2}{*}{ Reúso com aeração } & Esgoto tratado & 0,35 & Baixa & 64,7 & Média \\
\hline & $\mathrm{T}-2$ & 0,47 & Média & 68,4 & Média \\
\hline
\end{tabular}

Tabela 10 - Resultado da avaliação do custo ambiental (entropia - $\omega$ ) em termos de DB0, amônia, fósforo total e coliformes termotolerantes para os quatro sistemas avaliados

\begin{tabular}{lcccc} 
Sistema & \multicolumn{5}{c}{$\omega$} \\
\cline { 2 - 5 } & DBO & Amônia & FT & CT \\
\hline Lagoas de Estabilização & 164,67 & 25,36 & 0,0 & $1,7 \times 10^{7}$ \\
\hline Piscicultura convencional & $-23,77$ & $-0,26$ & 0,0 & 227,91 \\
\hline Reúso sem aeração & $-22,70$ & 3,82 & $-0,54$ & 355,73 \\
Reúso com aeração & $-2,85$ & 2,93 & $-0,60$ & 304,23
\end{tabular}

DBO: demanda bioquímica de oxigênio; FT: fósforo total; CT: coliformes termotolerantes.

O sistema de reúso sem aeração, em termos de DBO, apresentou resultado quase tão ruim quanto o da piscicultura convencional $(-22,70)$, porém, nesse caso, se está utilizando uma água que já tinha sua qualidade inicial comprometida. Já em termos de amônia e coliformes termotolerantes, esse sistema apresentou os melhores resultados entre os três sistemas de piscicultura avaliados (3,82 e - - ,54, respectivamente).

O reúso com aeração, em termos de $\mathrm{DBO}$, teve o melhor resultado entre os sistemas de piscicultura $(-2,85)$, praticamente não deteriorando a qualidade da água usada (efluente tratado). Já em termos de amônia e coliformes termotolerantes, apresentou resultados com valores compreendidos entre os obtidos pelos outros dois sistemas de piscicultura avaliados. Avaliando os resultados obtidos é possível afirmar que o sistema de reúso com aeração foi o que apresentou o menor custo ambiental.

\section{Discussão}

Os resultados apresentados neste trabalho confirmaram que a piscicultura convencional ocasionou efeitos deletérios na qualidade da água utilizada para abastecimento dos viveiros de piscicultura, produzindo um efluente de pior qualidade, em comparação com a água afluente. Porém, é válido salientar que toda atividade produtiva causa algum impacto negativo, sendo necessário o desenvolvimento de tecnologias e alternativas que reduzam esses impactos.

Castellani e Barrella (2006) afirmam que um dos principais pré-requisitos para a criação de peixes é que a água seja de boa qualidade e esteja disponível em quantidade adequada. No entanto, a maioria dos sistemas de piscicultura não possui unidades para filtragem e/ou tratamento dos seus efluentes, o que pode comprometer a qualidade da água a jusante dos cultivos. Dessa forma muitos cultivos acabam agindo como agentes de degradação da qualidade da água no meio natural.

Com isso, reforça-se a prática do reúso de águas residuárias em atividades agrícolas como uma ferramenta ambientalmente sustentável para o aumento da oferta hídrica. Quando se avaliam os resultados obtidos neste trabalho para o sistema denominado reúso sem aeração, observa-se que não houve alteração significativa na condição da qualidade do efluente da ETE, o que mostra que é possível se realizar o reúso em piscicultura, nas condições testadas, sem que haja prejuízo ambiental.

Quando se analisa o sistema reúso com aeração, observa-se que houve pequena melhoria na avaliação de sustentabilidade ambiental, levando-se a considerar que o reúso em piscicultura com aeração atua como um polimento do efluente da ETE, confirmando a sustentabilidade ambiental da atividade nessas condições.

\section{Conclusões}

No sistema de piscicultura convencional, observou-se o efeito degradante na qualidade da água, pela redução dos valores do ISA e IQA $A_{R P}$ e do elevado custo ambiental. Dessa forma, justifica-se a necessidade da utilização de fontes de água alternativas para o desenvolvimento dessa atividade. Assim, propõe-se a prática da aquicultura utilizando água de reúso para o abastecimento dos viveiros de cultivo como uma alternativa ambientalmente sustentável.

$\mathrm{Na}$ avaliação do sistema reúso sem aeração, concluiu-se que este não causou efeito deletério à qualidade do efluente da ETE, observando-se pequenas reduções dos valores $I_{S A} A_{R P}$ IQA $A_{R P}$ e do custo ambiental moderado, o que aponta a potencialidade do uso dessa água como fonte de abastecimento de viveiros de aquicultura. Dessa forma, aumenta-se a disponibilidade de água de melhor qualidade para fins mais nobres, bem como de água com qualidade adequada ao uso em aquicultura. 
$\mathrm{Na}$ análise do sistema reúso com aeração, observou-se que o seu efluente apresentou melhoria de qualidade, quando comparado com o efluente da ETE, indicada pelo aumento dos valores ISA $A_{R P}$ e IQA $A_{R P}$, e do baixo custo ambiental. Esses resultados indicam que o reúso com aeração resultou num polimento do esgoto tratado na ETE, revelando tanto o potencial de aproveitamento da água de reúso para o abastecimento de viveiros de aquicultura, como a sustentabilidade ambiental dessa prática, a qual, além de produzir proteína aproveitável como alimento para seres humanos, ainda melhora a qualidade do efluente que será lançado ao corpo de água receptor.

É válido salientar que os cultivos foram realizados com o fornecimento de ração comercial balanceada, o que ocasiona o aumento da carga orgânica no interior dos viveiros, prejudicando a qualidade da água. Dessa forma, torna-se necessária a realização de mais estudos no intuito de se encontrar a metodologia de cultivo mais adequada para água de reúso, para que se alcance a sustentabilidade ambiental da aquicultura nessas condições.

\section{Referências}

ANDRADE, D.C.; ROMEIRO, A.R. Capital natural, serviços ecossistêmicos e sistema econômico: rumo a uma Economia dos Ecossistemas. Texto para Discussão. IE/UNICAMP, n. 159, 2009.

AMERICAN PUBLIC HEALTH ASSOCIATION (APHA). Standard Methods for the examination of water and wastewater. $19^{a}$ ed. Washington, DC: APHA/AWWA - WPCF, 2005.

BORJA, P.C.; MORAES, L.R.S. Indicadores de saúde ambiental com enfoque para a área de saneamento. Parte 1 - aspectos conceituais e metodológicos. Eng. Sanit. Ambient., v. 8, n.1, p. 13-25, 2003.

BRASIL. Plano Estratégico de Desenvolvimento Sustentável do SemiÁrido - PDSA, Brasília, 2005. Disponível em: http://www.integracao.gov. $\mathrm{br} /$ desenvolvimentoregional/publicacoes/pdsa.asp. Acesso em: $11 \mathrm{fev}$. 2011.

CALIJURI, M.L.; SANTIAGO, A.F.; CAMARGO, R.A. et al. Estudo de indicadores de saúde ambiental e de saneamento em cidade do Norte do Brasil. Engenharia Sanitária \& Ambiental, v. 14, n. 1, p. 19-28, 2009.

CASTELLANI, D.; BARRELLA, W. Impactos da atividade de piscicultura na Bacia do Rio Ribeira do Iguape, SP - Brasil. Boletim do Instituto de Pesca, v. 32, n. 2, p. 161-171, 2006.

CAVALCANTI, P.F.F. et al. Pós-tratamento de efluentes anaeróbios em lagoas de polimento. In: CHERNICHARO, C.A.L. (coord.), Póstratamento de efluentes de reatores anaeróbios, Coletânea de Trabalhos Técnicos, vol. 2. Projeto PROSAB, FINEP. Belo Horizonte, 2001.

CEARÁ Portaria SEMACE 154, de 22 de Julho de 2002. Disponível em: http://www.semace.ce.gov.br/biblioteca/legislacao/conteudo_ legislacao.asp?cd=95. Acesso em: 31/12/2009.

CHRISTOFIDIS, D. Considerações sobre conflitos e uso sustentável em recursos hídricos. In: THEODORO, S.H. (org.) Conflitos e Uso sustentável dos Recursos Naturais. Rio de Janeiro: Ed. Garamond. 2002.

Olhares sobre a Política de Recursos Hídricos no Brasil: O caso da Bacia do Rio São Francisco. Brasília: UNB/Centro de Desenvolvimento Sustentável, 2001.

COLT, J. Water quality requirements for reuse systems. Aquacultural Enginnering, v. 34, p. 143-156, 2006.
ELER, M.N.; MILLANI, T.J. Métodos de estudos de sustentabilidade aplicados a aquicultura. Revista Brasileira de Zootecnia, v. 36, p. 33-44, 2007.

FLORENCIO, L. et al. Uso do Esgotos Tratados para Produção Animal. In: FLORENCIO, L.M. (Coord.). Tratamento e utilização de esgotos sanitários. Projeto PROSAB. Rio de Janeiro: ABES, 2006. p. 301-330.

KUBITZA, F. Tilápia - Tecnologia e planejamento na produção comercial. Jundiaí, SP: Acqua \& Imagem, 2000.

MATTAR NETO, J.; KRÜGER, C.M.; DZIEDZIC, M. Análise de indicadores ambientais no reservatório do Passaúna. Engenharia Sanitária \& Ambient., v .14, n. 2, p. 205-214, 2009.

MOTA, S. Gestão Ambiental de Recursos Hídricos. $3^{a}$ ed., atual. e rev. Rio de Janeiro: ABES, 343p., 2008.

MUGA, H.E.; MIHELCIC; J. R. Sustainability of wastewater treatment technologies. Journal of Environmental Management v. 88. p. 437-447. 2008.

NASCIMENTO, S.C.O.; ARAÚJO, R.C.P. Avaliação da sustentabilidade do projeto de piscicultura Curupati-peixe no açude Castanhão, Jaguaribara-CE. In: XLVI Congresso Da Sociedade Brasileira De Economia, Administração E Sociologia Rural. Rio Branco-AC, 2008.

PEREIRA, C.M. Avaliação do potencial do efluente de lagoas de estabilização para utilização na piscicultura. Florianópolis: UFSC, $173 f$. Tese, 2004.

PESCE, S.F., WUNDERLIN, D.A. Use of water quality indices to verify the impact of Córdoba city (Argentina) on Suquia River. Water Research, v. 34, p. 2915-2926, 2000.

PHILLIPS, M.J.; BEVERIDGE, M.C.M.; CLARK, R.M. Impact of Aquaculture on Water Resources. In: BRUNE, D.E.; TOMASSO, J.R. (Ed.). Aquaculture and water quality. Baton Rouge: The World Aquaculture Society. p.568591. 1991.

POLAZ, C.N.M; TEIXEIRA, B.A.N. Indicadores de sustentabilidade para a gestão municipal de resíduos sólidos urbanos: um estudo para São Carlos (SP). Engenharia Sanitária \& Ambiental, v. 14, n. 3, p. 411-420, 2009. 
RABELO, L.S. Indicadores de sustentabilidade: uma seqüência metodológica para a mensuração do progresso ao desenvolvimento sustentável. Dissertação (Mestrado em Desenvolvimento e Meio Ambiente) - PRODEMA, Universidade Federal do Ceará, Fortaleza, 2007.

SANTOS, E.S.; FURTADO NETO, M.; MOTA, S. et al. Cultivo de tilápia do Nilo em esgoto doméstico tratado, com diferentes taxas de alimentação. Revista DAE, v. 180, p. 4-11, 2009a.

SANTOS, E. S.; OLIVEIRA, M.A.; MOTA, S. et al. Crescimento e qualidade dos alevinos de tilápia do Nilo produzidos em esgoto doméstico tratado. Revista Ciência Agronômica, v. 40, n. 2, p.232-239, 2009 b.

SIMÕES F.S.; MOREIRA, A.B.; BISINOTI, M.C. et al. Water quality index as a simple indicator of aquaculture effects on aquatic bodies. Ecological Indicators, v. 08, p. 476-484, 2008.
TELLES, D.A. Água na agricultura e pecuária. In: REBOÇAS, A.C.; BRAGA, B.; TUNDISI, J.G. (Orgs.) Águas doces no Brasil: capital ecológico, uso e conservação. São Paulo: Escrituras. p. 305-337. 2006.

TIAGO, G.G.; GIANESELLA, S.M.F. O uso da água pela aqüicultura: estratégias e ferramentas de implementação de gestão. Boletim do Instituto de Pesca, São Paulo, v. 29, n. 1, p. 1-7. 2003.

TUNDISI, J.G. Recursos hídricos no futuro: problemas e soluções. Estudos Avançados. v. 22 n. 63, p. 7-16. 2008.

ZIMMERMANN, S.; FITZSIMMONS, K. Tilapicultura intensiva. In: CYRINO, J.E.P.; URBINATI, E.C.; FRACALOSSI, D.M.; CASTAGNOLLI, N. (Ed.) Tópicos especiais em piscicultura de água doce tropical intensiva. São Paulo: TecArt, 2004. 